\title{
Association between sedentary time and mortality across levels of frailty
}

\author{
Olga Theou PhD, Joanna M. Blodgett MSc, Judith Godin PhD, Kenneth Rockwood MD
}

- Cite as: CMAJ 2017 August 21;189:E1056-64. doi: 10.1503/cmaj.161034

CMAJ Podcasts: author interview at https://soundcloud.com/cmajpodcasts/161034-res

\begin{abstract}
BACKGROUND: Sedentary behaviours are associated with adverse health outcomes in middle-aged and older adults, even among those who exercise. We examined whether the degree of frailty affects the association between sedentary behaviours and higher risk of mortality.
\end{abstract}

METHODS: In this prospective cohort study, we used data from $3141 \mathrm{com}$ munity-dwelling adults 50 years of age or older from the 2003/04 and 2005/06 cohorts of the US National Health and Nutrition Examination Survey. Time engaged in sedentary behaviours was measured using uniaxial accelerometers, and frailty was based on a 46-item frailty index. Mortality data were linked up to 2011. We used Cox proportional hazard models to estimate the hazard ratio (HR) of sedentary behaviour.

RESULTS: We found that for people with low levels of frailty (frailty index score $\leq 0.1$ ), sedentary time was not predictive of mortality, regardless of physical activity level (adjusted HR 0.90, 95\% confidence interval $[\mathrm{Cl}] 0.70-1.15$ ). Among people who were vulnerable $(0.1<$ frailty index score $\leq 0.2)$ or frail (frailty index score $>0.2$ ), sedentary time was associated with higher mortality only among those who were physically inactive (not meeting the criterion for moderate physical activity) (HR 1.16,
95\% $\mathrm{Cl} 1.02-1.33$ for the group defined by $0.1<$ frailty index score $\leq 0.2$; HR $1.27,95 \% \mathrm{Cl} 1.11-1.46$ for the group defined by $0.2<$ frailty index score $\leq 0.3$; HR $1.34,95 \%$ Cl 1.19-1.50 for frailty index score $>0.3$ ).

INTERPRETATION: The effect of sedentary behaviours on mortality varied by level of frailty. Adults with the highest frailty level experienced the greatest adverse impact. Low frailty levels (frailty index score $\leq 0.1$ ) seemed to eliminate the increased risk of mortality associated with prolonged sitting, even among people who did not meet recommended physical activity guidelines.

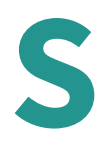
edentary behaviours are increasingly recognized as conferring health risks, independent of physical activity. The health benefits of physical activity are well established, and meeting minimum guidelines for physical activity is associated with reduced risk of many chronic conditions, functional decline, development of psychologic disorders and mortality. ${ }^{1-9}$ However, even among people who engage in periods of purposeful exercise, sedentary behaviours can increase the risk of adverse outcomes, such as metabolic risk factors, functional limitations, and all-cause and cardiovascular disease mortality. ${ }^{10-16}$ Even so, a recent meta-analysis showed that engaging in moderate physical activity, such as exercise, for at least 1 hour/day could eliminate the detrimental effects of prolonged sitting. ${ }^{17}$

Although most of the research on sedentary behaviours has focused on children and younger adults, middle-aged and older adults are the most sedentary group. A study using data from the Canadian Health Measures Survey showed that Canadians over the age of 40 are highly sedentary, spending about 9.5-10 of their wak- ing hours in sedentary behaviours (age 40-59 yr, $9.5 \mathrm{~h}$ for men and $9.8 \mathrm{~h}$ for women; age 60-79 yr, $9.9 \mathrm{~h}$ for men, $10 \mathrm{~h}$ for women). ${ }^{18}$ Only $14.6 \%$ of the Canadian population aged $40-59$ years and $13.1 \%$ of those aged $60-79$ years met the recommended 2.5 hours/ week of moderate-to-vigorous physical activity. ${ }^{18}$ Another study using data from the US National Health and Nutrition Examination Survey (NHANES) showed that participants over the age of 50 years spent on average 8.5 of their waking hours in sedentary behaviours. ${ }^{19}$ Only $7.1 \%$ of the population met the recommended 2.5 hours/week of moderate-to-vigorous physical activity. ${ }^{19}$

Reducing sedentary behaviours could improve health outcomes in middle-aged and older adults. Replacing 30 minutes of sedentary time with an equal amount of light activity or moderate-to-vigorous activity was associated with $14 \%$ and $50 \%$ reductions in risk of mortality, respectively. ${ }^{20,21}$ Even so, studies have shown a strong relation between sedentary behaviours and frailty, independent of moderate-to-vigorous activity. ${ }^{22,23}$ In addition, levels of sedentary behaviours closely corresponded to 
levels of frailty, with nonfrail individuals being sedentary for an average of 8.2 hours/day, whereas most frail individuals were sedentary for 9.6 hours/day. ${ }^{19}$ Yet no studies have examined whether the effect of sedentary behaviours on adverse health outcomes differs across levels of frailty. Such an understanding is vital if we are to systematically address sedentary behaviour among older people as a risk factor for adverse outcomes. We undertook this study to examine whether frailty level affects the association of sedentary behaviours with higher risk of mortality.

\section{Methods}

\section{Sample}

We used data from the 2003/04 and 2005/06 cohorts of the NHANES. The NHANES is a series of cross-sectional surveys of a communitybased sample. The NHANES investigators selected participants using a complex algorithm to ensure that the sample was nationally representative of the United States. ${ }^{24}$ For the current study, we included only participants 50 years of age or older who had a valid frailty index score, as well as accelerometer and mortality data. The NHANES investigators linked the NHANES data with death certificate data from the National Death Index to estimate mortality status. ${ }^{25}$ We calculated person-years of follow-up from the examination date until the date of death or censoring on Dec. 31, 2011.

\section{Frailty index}

Using the deficit accumulation approach, we used a 46-item frailty index that was constructed and validated in the NHANES population. ${ }^{19,26}$ We have previously published a complete list of deficits and coding. ${ }^{27}$ We calculated individual frailty index scores by dividing the number of deficits present in an individual by the total number of deficits considered; for example, an individual with 23 out of a possible 46 deficits would have a score of 0.5 (23/46). As noted above, we excluded from the analysis individuals with missing frailty data, defined as those with data missing on more than $20 \%$ of deficits. We categorized frailty index scores into 0.1-point increments to create 4 groups $(\leq 0.1,0.1<$ frailty index score $\leq 0.2,0.2<$ frailty index score $\leq 0.3$, and $>0.3$ ). These cut points are widely used in the literature. ${ }^{28,29}$ In our previous study using NHANES data, ${ }^{19}$ the first 2 categories were very similar but the third category was $0.2-$ 0.45 and the fourth category was greater than 0.45 . Although this categorization isolated people with severe frailty into 1 category (> 0.45), the group was very small $(n=122)$, with only 3 people meeting the guidelines of 2.5 hours/week of moderate-to-vigorous physical activity and only 2 reporting vigorous activity. ${ }^{19}$ Therefore, for the current study, we used 0.3 as the cut point for the fourth group, which identified people with moderate-to-severe frailty.

\section{Physical activity and measures of sedentary behaviour}

Each participant wore a uniaxial AM-7164 accelerometer (ActiGraph, LLC) on an elastic waist belt for a 7-day period. NHANES investigators instructed participants to wear the accelerometer during all waking hours and to remove it during bathing or swimming activities. We excluded all data marked as nonreliable or not in calibration; only the data of those who wore the accelerometer for a minimum of 10 hours on 4 separate days were included in the analysis. ${ }^{18,30}$ Using validated NHANES cut points, ${ }^{19,30}$ we defined sedentary behaviour as $0-100$ counts/minute and moderate-tovigorous physical activity as greater than 2020 counts/minute. We analyzed sedentary behaviour as both a continuous and a categorical variable, where low sedentary behaviour was less than 7 hours/ day, intermediate sedentary behaviour was 7 to 10 hours/day, and high sedentary behaviour was more than 10 hours/day. We also dichotomized physical activity as meeting or not meeting the recommendations of both the Canadian Society for Exercise Physiology $^{4}$ and the American College of Sports Medicine ${ }^{31,32}$ (2.5 h/wk of moderate-to-vigorous physical activity). Participants self-reported vigorous activity by stating whether they had done any activity that caused heavy sweating or large increases in breathing or heart rate for a period of at least 10 minutes over the past 30 days.

\section{Statistical analysis}

We conducted all statistical analyses using SPSS software, version 21 (IBM). We calculated mortality rates for all participants after stratifying by frailty index level, by sedentary time and by accelerometermeasured and self-reported physical activity. We used the Pearson $\chi^{2}$ test to examine associations between mortality and frailty group, sedentary time and physical activity. We used Cox proportional hazard models to estimate the hazard ratio of sedentary behaviour. To control for the fact that participants entered the study at different ages, we used residual proportional hazards regression. ${ }^{33}$ In the first stage, time-varying covariables (i.e., frailty, moderate-to-vigorous physical activity and self-reported exercise) were individually regressed on age, and the residuals from each of these regressions were saved. In the second stage, we ran Cox regressions with age and the saved residuals replacing their corresponding covariables. Because we were interested in adults 50 years of age or older, we used age as the time scale, with age 50 years as the time origin. The basic model examined the risk of death associated with sedentary behaviour controlling for significant covariables; additional models adjusted for both objectively and subjectively measured physical activity. We then stratified the analyses by objectively measured physical activity $(\geq 2.5 \mathrm{~h} / \mathrm{wk}$ or $<2.5 \mathrm{~h} /$ wk of moderate-to-vigorous physical activity) and selfreported vigorous physical activity in the last 30 days (yes or no) and then further stratified by frailty index level. We stratified Kaplan-Meier survival curves, using time from assessment as the time scale, by both frailty index group and physical activity. We used statistical weights for demographic characteristics and mortality rates to ensure that the sample was representative of the US population.

We included in the regression models the following covariables, which have been shown to be related to sedentary time and frailty: age (yr), sex (male, female), education (less than high school, high school, some college or associate degree, college graduate or more), race/ethnicity (Mexican American or other Hispanic, non-Hispanic white, non-Hispanic black, other), marital status (married, widowed, divorced or separated, never married), smoking status (never, past, current), body mass index ( $<18.5$, 18.5-24.9, 25-29.9, $\geq 30$ ), employment status (working full-time, not working full-time), accelerometer wear time (h) and study cohort (2003/04, 2005/06). We considered annual household income and alcohol use as potential covariables but did not include them because of missing data. 


\section{Ethics approval}

The NHANES survey protocol was approved by the Institutional Review Board of the Centers for Disease Control and Prevention. All patients provided written informed consent.

\section{Results}

Of the 20470 participants from the 2003/04 and 2005/06 NHANES cohorts, 4874 individuals were aged 50 years or older. After exclusion of participants with missing accelerometer data ( $n=1421)$, frailty index data $(n=307)$ and mortality data $(n=5)$, the final sample size was 3141 (Appendix 1, available at www.cmaj.ca/lookup/
suppl/doi:10.1503/cmaj.161034/-/DC1). Those excluded were slightly older than those included in the analysis (mean age \pm standard deviation $65.9 \pm 12.0$ v. $63.3 \pm 10.1 \mathrm{yr}$ ), with slightly higher levels of disability based on activities of daily living (for women, $54.3 \%$ of those excluded v. $53.7 \%$ of those included had disability; for men, $19.8 \%$ of those excluded v. $17.0 \%$ of those included had disability). On average, accelerometer data were available for 6.24 \pm 0.94 days and $14.2 \pm 1.7$ daily hours for each participant. The mean duration of follow-up from the date of baseline assessment until the date of death or censoring was $6.5 \pm 1.6$ years.

All of the characteristics of this sample except smoking differed by frailty index (Table 1 ). The weighted mortality rate was

Table 1: Characteristics of participants by frailty level

\begin{tabular}{|c|c|c|c|c|}
\hline \multirow[b]{2}{*}{ Characteristic } & \multicolumn{4}{|c|}{ FI score; $\%$ of participants* } \\
\hline & $\begin{array}{c}\leq 0.1 \\
n=766\end{array}$ & $\begin{array}{c}0.1<\mathrm{FI} \leq 0.2 \\
n=1121\end{array}$ & $\begin{array}{c}0.2<\mathrm{FI} \leq 0.3 \\
n=681\end{array}$ & $\begin{array}{c}>0.3 \\
n=573\end{array}$ \\
\hline Age, $y r$, mean \pm SD & $57.9 \pm 7.2$ & $63.1 \pm 9.5$ & $67.7 \pm 9.9$ & $70.0 \pm 10.8$ \\
\hline Sex, female & 45.7 & 56.7 & 53.9 & 63.4 \\
\hline \multicolumn{5}{|l|}{ Race/ethnicity } \\
\hline Non-Hispanic white & 81.6 & 81.5 & 81.9 & 79.6 \\
\hline Non-Hispanic black & 6.9 & 7.9 & 7.8 & 12.6 \\
\hline Hispanic & 7.3 & 7.0 & 4.8 & 4.2 \\
\hline Other & 4.2 & 3.6 & 5.5 & 3.7 \\
\hline \multicolumn{5}{|l|}{ Education } \\
\hline Less than high school & 11.2 & 17.8 & 23.6 & 32.8 \\
\hline High school & 23.2 & 26.8 & 30.3 & 30.7 \\
\hline Some college/associate education & 32.6 & 29.1 & 27.1 & 27.0 \\
\hline College graduate or more & 32.9 & 26.3 & 19.0 & 9.5 \\
\hline \multicolumn{5}{|l|}{ Marital status } \\
\hline Married & 76.5 & 70.1 & 66.1 & 50.3 \\
\hline Widowed & 5.8 & 12.3 & 16.8 & 30.4 \\
\hline Divorced or separated & 14.2 & 13.4 & 13.5 & 15.2 \\
\hline Never married & 3.4 & 4.2 & 3.7 & 4.1 \\
\hline Full-time working & 57.8 & 37.3 & 18.7 & 4.8 \\
\hline \multicolumn{5}{|l|}{ Smoking status } \\
\hline Never & 49.4 & 47.9 & 42.6 & 45.0 \\
\hline Past & 33.8 & 37.2 & 40.9 & 38.1 \\
\hline Current & 16.8 & 14.9 & 16.5 & 16.8 \\
\hline \multicolumn{5}{|l|}{ Body mass index } \\
\hline Underweight & 1.2 & 0.9 & 1.4 & 1.4 \\
\hline Normal & 33.1 & 27.2 & 21.1 & 25.5 \\
\hline Overweight & 39.9 & 40.4 & 36.4 & 31.0 \\
\hline Obese & 25.8 & 31.4 & 41.1 & 42.1 \\
\hline Accelerometer time, $\mathrm{h}$, mean $\pm \mathrm{SD}$ & $14.6 \pm 1.5$ & $14.3 \pm 1.7$ & $14 \pm 1.6$ & $13.7 \pm 1.9$ \\
\hline
\end{tabular}


$12.0 \%$ (550/3141) or 18.7 deaths per 1000 person-years (Table 2). Mortality rate increased with higher frailty index levels, both in the overall sample $(p<0.001)$ and when stratified by sedentary time or physical activity $(p<0.001)$.

Cox regression models showed significant interaction between frailty and sedentary behaviour, even when objectively measured and self-reported physical activity were added to the model (Table 3). When the analysis was stratified by physical activity, we found that for those who met the moderate-to-vigorous physical activity requirements and for those who reported vigorous physical activity, there was no significant interaction between frailty and sedentary behaviour, and sedentary time was not associated with mortality (Table 3 ). When the analysis was stratified by frailty level, we found that sedentary behaviour remained associated with mortality in the 3 highest frailty index groups in a fully adjusted model (frailty index score $>0.1$ ) but not in the group with low frailty (frailty index score $\leq 0.1$ ) (Table 4). There was no association between sedentary behaviour and mortality among those who met the requirements for moderateto-vigorous physical activity or self-reported vigorous physical activity in the last month (Table 4).

Kaplan-Meier curves showed a significant separation among low, intermediate and high levels of sedentary behaviour. This pattern held true for the 3 highest frailty index groups of the overall sample $(p<0.05)$ and for those who were physically inac- tive by objective measurement ( $p<0.05$; Figure 1$)$ or did not report vigorous physical activity in the past month $(p<0.05)$.

\section{Interpretation}

This large, nationally representative study of the US population showed the degree to which the accumulation of age-related health deficits affects the association between sedentary behaviours and higher risk of mortality. We found that for people who had low levels of frailty (frailty index score $\leq 0.1$ ), sedentary time was not predictive of mortality, regardless of physical activity level. For those who were vulnerable $(0.1<$ frailty index score $\leq 0.2$ ) or frail (frailty index score $>0.2$ ), sedentary time was associated with higher mortality only among those who were physically inactive (not meeting the requirement for moderate physical activity or not reporting participation in vigorous activity). Thus, among people who are inactive and vulnerable or frail, sitting time increases mortality risk, but among those who are nonfrail or active, sitting time does not affect the risk of mortality.

NHANES is a cross-sectional survey, and mortality data were provided through linkage to death certificate data. Although this approach increases the accuracy of the data, it did not allow us to examine whether changes in sitting time affect the risk of death. NHANES collected accelerometer data only from the

\section{Table 2: Mortality rate stratified by frailty level, sedentary time and physical activity}

\begin{tabular}{|c|c|c|c|c|}
\hline \multirow[b]{2}{*}{ Physical activity category } & \multicolumn{4}{|c|}{ FI score; mortality data* } \\
\hline & $\leq 0.1$ & $0.1<\mathrm{FI} \leq 0.2$ & $0.2<\mathrm{FI} \leq 0.3$ & $>0.3$ \\
\hline All participants & $\begin{array}{c}42 / 766 \\
(2.8,4.1)\end{array}$ & $\begin{array}{l}140 / 1121 \\
(8.7,13.2)\end{array}$ & $\begin{array}{c}153 / 681 \\
(16.3,25.8)\end{array}$ & $\begin{array}{c}215 / 573 \\
(35.3,61.6)\end{array}$ \\
\hline \multicolumn{5}{|l|}{ Sedentary behaviour } \\
\hline $\operatorname{Low}(<7 \mathrm{~h} / \mathrm{d})$ & $\begin{array}{c}12 / 209 \\
(2.9,4.2)\end{array}$ & $\begin{array}{c}25 / 251 \\
(7.7,11.5)\end{array}$ & $\begin{array}{c}9 / 87 \\
(5.8,8.7)\end{array}$ & $\begin{array}{c}11 / 62 \\
(20.4,33.0)\end{array}$ \\
\hline Intermediate $(7-10 \mathrm{~h} / \mathrm{d})$ & $\begin{array}{c}25 / 439 \\
(2.8,4.1)\end{array}$ & $\begin{array}{c}74 / 653 \\
(7.5,11.5)\end{array}$ & $\begin{array}{c}89 / 437 \\
(14.3,22.3)\end{array}$ & $\begin{array}{c}101 / 310 \\
(30.1,50.9)\end{array}$ \\
\hline High ( > 10 h/d) & $\begin{array}{c}5 / 118 \\
(2.4,3.1)\end{array}$ & $\begin{array}{c}41 / 217 \\
(14.0,22.2)\end{array}$ & $\begin{array}{c}55 / 157 \\
(27.5,47.3)\end{array}$ & $\begin{array}{c}103 / 201 \\
(49.6,95.9)\end{array}$ \\
\hline \multicolumn{5}{|c|}{ Objectively measured physical activity $\uparrow$} \\
\hline Physically inactive & $\begin{array}{c}32 / 475 \\
(4.0,5.8)\end{array}$ & $\begin{array}{c}119 / 856 \\
(9.6,14.7)\end{array}$ & $\begin{array}{c}150 / 621 \\
(17.7,28.4)\end{array}$ & $\begin{array}{c}206 / 536 \\
(36.2,63.6)\end{array}$ \\
\hline Physically active & $\begin{array}{c}10 / 291 \\
(1.1,1.8)\end{array}$ & $\begin{array}{c}21 / 265 \\
(6.1,9.0)\end{array}$ & $\begin{array}{c}3 / 60 \\
(2.0,2.7)\end{array}$ & $\begin{array}{c}9 / 37 \\
(23.2,34.9)\end{array}$ \\
\hline \multicolumn{5}{|l|}{ Self-reported physical activity } \\
\hline Physically inactive & $\begin{array}{c}35 / 528 \\
(3.1,4.8)\end{array}$ & $\begin{array}{c}122 / 901 \\
(9.6,14.6)\end{array}$ & $\begin{array}{c}147 / 623 \\
(17.1,27.2)\end{array}$ & $\begin{array}{c}210 / 551 \\
(35.8,63.0)\end{array}$ \\
\hline Physically active & $\begin{array}{c}7 / 238 \\
(2.2,3.4)\end{array}$ & $\begin{array}{c}18 / 220 \\
(5.9,9.0)\end{array}$ & $\begin{array}{c}6 / 58 \\
(9.9,15.5)\end{array}$ & $\begin{array}{c}5 / 22 \\
(20.8,30.1)\end{array}$ \\
\hline \multicolumn{5}{|c|}{$\begin{array}{l}\text { Note: } \mathrm{Fl}=\text { frailty index. } \\
\text { "Data are presented as number who died/total number (unweighted), followed by weighted } \% \text { dead at follow-up and mortality per } 1000 \text { person- } \\
\text { years in parentheses. Follow-up (to time of death or censoring on Dec. } 31,2011 \text { ) was on average } 6.5 \pm 1.6 \text { years from the baseline assessment. } \\
\text { tMeeting the recommended guidelines of } 2.5 \text { hours/week of moderate-to-vigorous physical activity. } \\
\text { łSelf-reported vigorous physical activity for a period of at least } 10 \text { minutes over the past } 30 \text { days. }\end{array}$} \\
\hline
\end{tabular}


Table 3: Relation between sedentary time and time to death, stratified by physical activity

Model $^{\star}$

HR $(95 \% \mathrm{Cl})$

\section{All participants}

Sedentary time, per hour, adjusted for age

$1.15(1.11-1.20)$

Model including frailty and sedentary time $\times$ frailty interaction, fully adjusted $\dagger$

Sedentary time, per hour

$1.19(1.11-1.27)$

Frailty, per 0.01 score

$1.03(1.03-1.04)$

Sedentary time $\times$ frailty interaction

$1.00(1.00-1.01)$

Model including frailty, objectively measured activity, and sedentary time $\times$ frailty interaction, fully adjusted $\dagger$

Sedentary time, per hour

$1.18(1.10-1.26)$

Frailty, per 0.01 score

$1.03(1.03-1.04)$

Sedentary time $\times$ frailty interaction

$1.00(1.00-1.01)$

Objectively measured activity $\ddagger$

$0.80(0.57-1.12)$

Model including frailty, self-reported activity, and sedentary time $\times$ frailty interaction, fully adjusted $\dagger$

Sedentary time, per hour

$1.19(1.11-1.27)$

Frailty, per 0.01 score

$1.03(1.03-1.04)$

Sedentary time $\times$ frailty interaction

$1.00(1.00-1.01)$

Self-reported activity§

$0.77(0.54-1.09)$

\section{Objectively measured activity}

Physically inactive participants

Sedentary time, per hour, adjusted for age

$1.15(1.11-1.20)$

Model including frailty and sedentary time $\times$ frailty interaction, fully adjusted $\dagger$

Sedentary time, per hour

$1.20(1.12-1.29)$

Frailty, per 0.01 score

$1.03(1.03-1.04)$

Sedentary time $\times$ frailty interaction

$1.00(1.00-1.01)$

Physically active participants

Sedentary time, per hour, adjusted for age

$0.99(0.84-1.18)$

Model including frailty and sedentary time $\times$ frailty interaction, fully adjusted $\dagger$

Sedentary time, per hour

$0.98(0.78-1.24)$

Frailty, per 0.01 score

$1.06(1.02-1.10)$

Sedentary time $\times$ frailty interaction

$1.01(0.99-1.03)$

\section{Self-reported activity§}

Physically inactive participants

Sedentary time, per hour, adjusted for age

$1.16(1.11-1.21)$

Model including frailty and sedentary time $\times$ frailty interaction, fully adjusted $\dagger$

Sedentary time, per hour

$1.21(1.13-1.29)$

Frailty, per 0.01 score

$1.04(1.03-1.04)$

Sedentary time $\times$ frailty interaction

$1.00(1.00-1.01)$

Physically active participants

Sedentary time, per hour, adjusted for age

$0.93(0.77-1.14)$

Model including frailty and sedentary time $\times$ frailty interaction, fully adjusted $\dagger$

Sedentary time, per hour

$0.85(0.64-1.15)$

Frailty, per 0.01 score

$1.04(1.00-1.07)$

Sedentary time $\times$ frailty interaction

$0.99(0.97-1.01)$

Note: $\mathrm{Cl}=$ confidence interval, $\mathrm{HR}=$ hazard ratio.

*All Cox regression models were adjusted for age.

†Model also adjusted for sex, race/ethnicity, education, marital status, employment status, smoking, body mass index, time wearing accelerometer and study cohort.

tMeeting the recommended guidelines of 2.5 hours/week of moderate-to-vigorous physical activity.

$\S$ Self-reported vigorous physical activity for a period of at least 10 minutes over the past 30 days. 
2003/04 and 2005/06 cohorts; therefore, more recent data for objectively measured physical activity levels were not available to us through this survey. We expect that if we had been able to use more recent data in our study, we could have shown a slightly higher level of physical activity among participants; however, we do not expect that the relation between sedentary behaviours and mortality would have been different. A previous study using the NHANES self-reported physical activity data showed that more participants in the 2011/12 cycle than the $2007 / 08$ cycle met the physical activity guidelines $(21.7 \% \mathrm{v}$. $27.2 \%$ ); however, the proportion of people reporting no leisure time physical activity remained stable between the 2 cohorts. ${ }^{34}$

Multiple studies have shown that sedentary behaviours are associated with mortality in middle-aged and older adults. ${ }^{20,21,35,36}$ Wijndaele and colleagues ${ }^{35}$ showed that time spent watching television was associated with all-cause mortality in a populationbased cohort (the European Prospective Investigation into Cancer and Nutrition study) of about 13000 people (62 $\pm 9 \mathrm{yr}$ ), even after stratification by age, sex, education, body mass index and energy expenditure for total physical activity. Similarly, Matthews and colleagues ${ }^{36}$ showed that time spent watching television was associated with all-cause mortality in 240819 adults (50-71 yr) from the Diet and Health Study of the National Institutes of Health and the American Association of Retired Persons, even after stratification by age, sex, education, race, body mass index, smoking, chronic conditions and diet quality. Fishman and colleagues ${ }^{21}$ showed that replacing objectively measured sedentary time with light activity was associated with a reduction in mortality risk in NHANES, and the sex-stratified findings were similar to the findings for men and women combined. The current study showed that stratification by frailty level had an impact on the effect of sedentary behaviours on mortality. Differences from these previous studies may be related to levels of frailty representing the overall health state of an individual and the frailty index being a more sensitive measure for change in health than other measures. Similar to our study, a recent meta-analysis including data from more than 1 million individuals showed that among people who were physically active ( $>35.5$ metabolic equivalent of taskhours per week or about 60-75 min/d), sedentary time was not predictive of all-cause mortality. ${ }^{17}$

Table 4: Relation between sedentary time and time to death, stratified by frailty index

\begin{tabular}{|c|c|c|c|c|}
\hline Model ${ }^{\star}$ & $\leq 0.1$ & $0.1<\mathrm{FI} \leq 0.2$ & $0.2<\mathrm{FI} \leq 0.3$ & $>0.3$ \\
\hline Sedentary time, per hour, adjusted for age & $0.82(0.69-0.99)$ & $1.08(0.99-1.18)$ & $1.23(1.13-1.34)$ & $1.13(1.07-1.20)$ \\
\hline Sedentary time, per hour, fully adjusted $\dagger$ & $0.90(0.70-1.14)$ & $1.14(1.01-1.28)$ & $1.31(1.14-1.50)$ & $1.35(1.21-1.50)$ \\
\hline Sedentary time, per hour & $0.90(0.70-1.15)$ & $1.13(1.00-1.28)$ & $1.27(1.11-1.46)$ & $1.36(1.22-1.52)$ \\
\hline Objectively measured activity $\ddagger$ & $1.01(0.42-2.39)$ & $0.92(0.56-1.52)$ & $0.20(0.05-0.83)$ & $1.23(0.59-2.54)$ \\
\hline \multicolumn{5}{|c|}{ Model including self-reported activity, fully adjusted $\dagger$} \\
\hline Sedentary time, per hour & $0.90(0.70-1.14)$ & $1.14(1.01-1.29)$ & $1.31(1.14-1.50)$ & $1.34(1.21-1.49)$ \\
\hline Sedentary time, per hour, fully adjusted $\dagger$ & $1.03(0.77-1.36)$ & $1.16(1.02-1.33)$ & $1.27(1.11-1.46)$ & $1.34(1.19-1.50)$ \\
\hline \multicolumn{5}{|l|}{ Physically active participants } \\
\hline Sedentary time, per hour, fully adjusted $\dagger$ & \multicolumn{2}{|c|}{$0.84(0.62-1.12)$ ฯ } & \multicolumn{2}{|c|}{$2.31(0.66-8.13) \leadsto$} \\
\hline \multicolumn{5}{|l|}{ Self-reported activity§ } \\
\hline \multicolumn{5}{|l|}{ Physically inactive participants } \\
\hline Sedentary time, per hour, fully adjusted $\dagger$ & $0.92(0.69-1.22)$ & $1.16(1.02-1.33)$ & $1.32(1.15-1.51)$ & $1.32(1.19-1.47)$ \\
\hline \multicolumn{5}{|l|}{ Physically active participants } \\
\hline Sedentary time, per hour, fully adjusted $\dagger$ & \multicolumn{2}{|c|}{$1.03(0.75-1.41)$ ฯ } & \multicolumn{2}{|c|}{ Sample size too small } \\
\hline
\end{tabular}




\section{Limitations}

Our study had some limitations, and our findings should be interpreted with caution. As is typical for studies using physical activity monitors, almost one-third of participants in our study were missing accelerometer data, and these participants seemed to have higher levels of frailty. Thus, our sample size was substantially reduced, especially among the group with the highest level of frailty, which made it necessary to merge frailty groups for some analyses and prevented us from isolating those with severe frailty (frailty index score $>0.45$ ) into 1 category. Future studies will need to examine the effect of sedentary behaviours on people with higher levels of frailty using other data sets. Furthermore, we could not include income and alcohol as covariables because of missing data. Another limitation relates to the accelerometer cut points used in this study to assess the time spent in sedentary behaviours and moderate-to-vigorous physical activ- ity; although widely used, these cut points are based on studies involving healthier older adults and we may therefore have overestimated sedentary time in the participants with higher frailty levels. Even so, accelerometers are reliable measures of sedentary behaviours, have been validated in older adults with and without impaired function ${ }^{37-42}$ and can also be used for people with cognitive problems who cannot complete questionnaires about their daily levels of physical activity. ${ }^{43,44}$ Finally, although the HRs per hour of sedentary behaviour were relatively high for most models, the lower limit of some confidence intervals was close to 1.00 .

\section{Conclusion}

This study has shown that the effect of sedentary behaviours on mortality differs across levels of frailty among people who are physically inactive, with people who are most frail experiencing

Frailty index (FI) score

$\leq 0.1$

All participants



Physically inactive

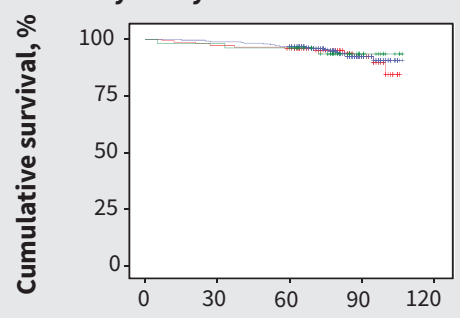

$0.1<\mathrm{FI} \leq 0.2$
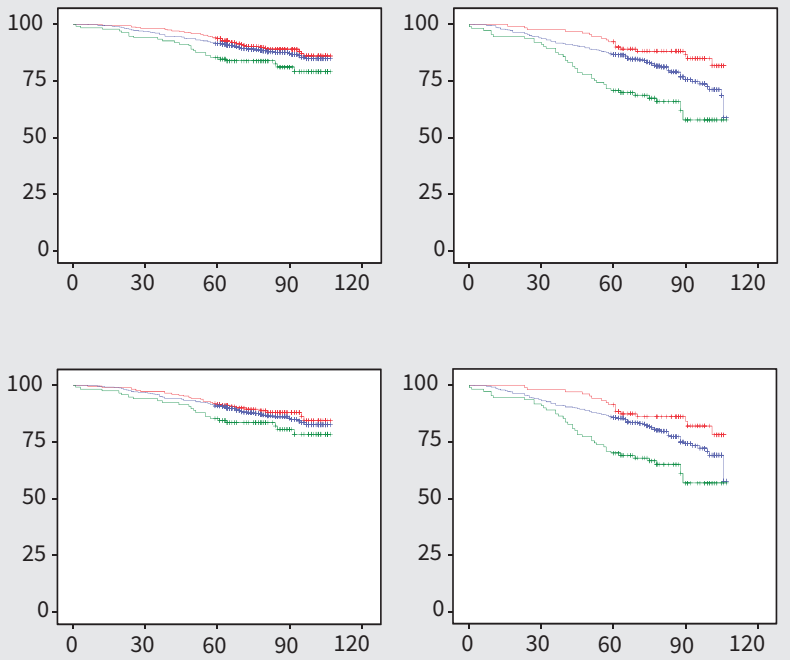

$0.2<\mathrm{FI} \leq 0.3$

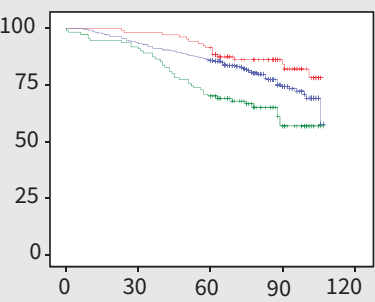



$>0.3$

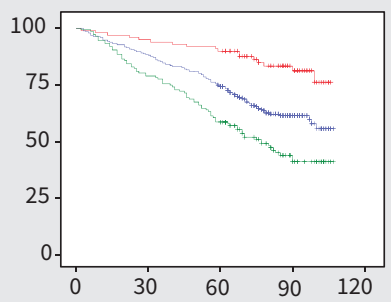

Physically active*
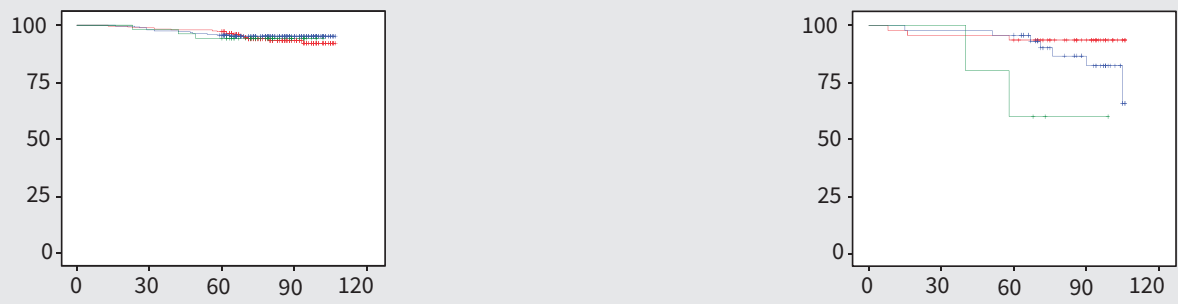

Time to death, mo

Level of sedentary behaviour: $-\operatorname{Low}(<7 \mathrm{~h} / \mathrm{d})-\operatorname{Intermediate}(7-10 \mathrm{~h} / \mathrm{d})-\operatorname{High}(>10 \mathrm{~h} / \mathrm{d})$

Figure 1: Kaplan-Meier Curves stratified by frailty index score and whether participants were physically active or inactive (as determined by objective measurement). *For the physically active participants, the groups with frailty index score $\leq 0.1$ and $0.1<$ frailty index score $\leq 0.2$ were merged, as were the groups with $0.2<$ frailty index score $\leq 0.3$ and frailty index score $>0.3$, because of small sample sizes. 
the greatest impact. For these individuals, it appears that all hours of the day have an effect on health, not just those spent in physical activity of moderate-to-vigorous intensity. Similar to the situation for tobacco control, where doctors do not emphasize the benefits of nonsmoking, but rather the harms of smoking, we should also emphasize the harms of sedentary behaviours rather than just the benefits of physical activity. ${ }^{5}$ This is an important public health message that should be part of a larger promotion of the importance of healthy lifestyle behaviours. ${ }^{45}$ The first Canadian 24-hour movement guideline for children and youth, released in June 2016, suggested that sitting for extended periods should be limited and that recreational screen time should not exceed 2 hours a day. Similar guidelines are needed for middle-aged and older adults. ${ }^{46}$ Future studies should also examine whether the degree of frailty affects the association of sedentary behaviours with other adverse outcomes, such as functional and cognitive decline, and whether interventions to reduce sitting time should be modified on the basis of frailty level of participants. A randomized clinical trial should examine whether reducing sedentary behaviours can prevent or delay frailty.

\section{References}

1. Lee IM, Shiroma EJ, Lobelo F, et al. Effect of physical inactivity on major noncommunicable diseases worldwide: an analysis of burden of disease and life expectancy. Lancet 2012;380:219-29.

2. Paterson DH, Warburton DE. Physical activity and functional limitations in older adults: a systematic review related to Canada's physical activity guidelines. Int J Behav Nutr Phys Act 2010;7:38.

3. Middleton LE, Yaffe K. Promising strategies for the prevention of dementia. Arch Neurol 2009;66:1210-5.

4. Tremblay MS, Warburton DE, Janssen I, et al. New Canadian physical activity guidelines. Appl Physiol Nutr Metab 2011;36:36-46, 47-58.

5. Wen CP, Wu X. Stressing harms of physical inactivity to promote exercise. Lancet 2012;380:192-3.

6. Gregg EW, Cauley JA, Stone K, et al.; Study of Osteoporotic Fractures Research Group. Relationship of changes in physical activity and mortality among older women. JAMA 2003;289:2379-86.

7. Hubbard RE, Fallah N, Searle SD, et al. Impact of exercise in community-dwelling older adults. PLoS One 2009;4:e6174.

8. Paterson DH, Jones GR, Rice CL. Ageing and physical activity: evidence to develop exercise recommendations for older adults. Can J Public Health 2007;98 Suppl 2:S69-108.

9. Warburton DE, Nicol C, Bredin SS. Health benefits of physical activity: the evidence. CMAJ 2006;174:801-9.

10. Hamilton MT, Healy GN, Dunstan DW, et al. Too little exercise and too much sitting: inactivity physiology and the need for new recommendations on sedentary behavior. Curr Cardiovasc Risk Rep 2008;2:292-8.

11. Lord S, Chastin SF, Mclnnes L, et al. Exploring patterns of daily physical and sedentary behaviour in community-dwelling older adults. Age Ageing 2011;40:205-10.

12. Seguin R, Lamonte M, Tinker L, et al. Sedentary behavior and physical function decline in older women: findings from the Women's Health Initiative. J Aging Res 2012;2012:271589.

13. Owen N, Healy GN, Matthews CE, et al. Too much sitting: the population health science of sedentary behavior. Exerc Sport Sci Rev 2010;38:105-13.

14. Warren TY, Barry V, Hooker SP, et al. Sedentary behaviors increase risk of cardiovascular disease mortality in men. Med Sci Sports Exerc 2010;42:879-85.
15. Patel AV, Bernstein L, Deka A, et al. Leisure time spent sitting in relation to total mortality in a prospective cohort of US adults. Am J Epidemiol 2010; 172:419-29.

16. Katzmarzyk PT, Church TS, Craig CL, et al. Sitting time and mortality from all causes, cardiovascular disease, and cancer. Med Sci Sports Exerc 2009; 41:998-1005.

17. Ekelund U, Steene-Johannessen J, Brown WJ, et al.; Lancet Physical Activity Series 2 Executive Committe; Lancet Sedentary Behaviour Working Group. Does physical activity attenuate, or even eliminate, the detrimental association of sitting time with mortality? A harmonised meta-analysis of data from more than 1 million men and women. Lancet 2016;388:1302-10.

18. Colley RC, Garriguet D, Janssen I, et al. Physical activity of Canadian adults: accelerometer results from the 2007 to 2009 Canadian Health Measures Survey. Health Rep 2011;22:7-14.

19. Blodgett J, Theou O, Kirkland S, et al. The association between sedentary behaviour, moderate-vigorous physical activity and frailty in NHANES cohorts. Maturitas 2015;80:187-91.

20. Schmid D, Ricci C, Baumeister SE, et al. Replacing sedentary time with physical activity in relation to mortality. Med Sci Sports Exerc 2016;48:1312-9.

21. Fishman El, Steeves JA, Zipunnikov V, et al. Association between objectively measured physical activity and mortality in NHANES. Med Sci Sports Exerc 2016;48:1303-11.

22. Da Silva Coqueiro R, De Queiroz BM, Oliveira DS, et al. Cross-sectional relationships between sedentary behavior and frailty in older adults. J Sports Med Phys Fitness 2017;57:825-30.

23. Song J, Lindquist LA, Chang RW, et al. Sedentary behavior as a risk factor for physical frailty independent of moderate activity: results from the osteoarthritis initiative. Am J Public Health 2015;105:1439-45.

24. National Health and Nutrition Examination Survey data. Atlanta: Centers for Disease Control and Prevention, National Center for Health Statistics; 2014. Available: www.cdc.gov/nchs/nhanes.htm (accessed 2017 May 18).

25. National Health and Nutrition Examination Survey (NHANES) 1999-2004 linked mortality files: restricted-use file layout. Atlanta: Centers for Disease Control and Prevention. Available: https://www.cdc.gov/nchs/data/datalinkage/ nh99_04_mortality_file_layout.pdf (accessed 2017 May 8).

26. Searle SD, Mitnitski A, Gahbauer EA, et al. A standard procedure for creating a frailty index. BMC Geriatr 2008;8:24.

27. Blodgett J, Theou O, Kirkland S, et al. Frailty in NHANES: comparing the frailty index and phenotype. Arch Gerontol Geriatr 2015;60:464-70.

28. Blodgett JM, Theou O, Howlett SE, et al. A frailty index based on laboratory deficits in community-dwelling men predicted their risk of adverse health outcomes. Age Ageing 2016;45:463-8.

29. Miller AJ, Theou O, McMillan M, et al. Dysnatremia in relation to frailty and age in community-dwelling adults in the National Health and Nutrition Examination Survey. J Gerontol A Biol Sci Med Sci 2017;72:376-81.

30. Troiano RP, Berrigan D, Dodd KW, et al. Physical activity in the United States measured by accelerometer. Med Sci Sports Exerc 2008;40:181-8.

31. American College of Sports Medicine position stand: exercise and physical activity for older adults. Med Sci Sports Exerc 1998;30:992-1008.

32. Tremblay MS, Colley RC, Saunders TJ, et al. Physiological and health implications of a sedentary lifestyle. Appl Physiol Nutr Metab 2010;35:725-40.

33. Sperrin M, Buchan I. Modelling time to event with observations made at arbitrary times. Stat Med 2013;32:99-109.

34. Keadle SK, McKinnon R, Graubard BI, et al. Prevalence and trends in physical activity among older adults in the United States: a comparison across three national surveys. Prev Med 2016;89:37-43.

35. Wijndaele $\mathrm{K}$, Brage $\mathrm{S}$, Besson $\mathrm{H}$, et al. Television viewing time independently predicts all-cause and cardiovascular mortality: the EPIC Norfolk study. Int J Epidemiol 2011;40:150-9. 
36. Matthews CE, George SM, Moore SC, et al. Amount of time spent in sedentary behaviors and cause-specific mortality in US adults. Am J Clin Nutr 2012;95: 437-45.

37. Copeland JL, Esliger DW. Accelerometer assessment of physical activity in active, healthy older adults. J Aging Phys Act 2009;17:17-30.

38. Harris TJ, Owen CG, Victor CR, et al. A comparison of questionnaire, accelerometer, and pedometer: measures in older people. Med Sci Sports Exerc 2009;41:1392-402.

39. Pruitt LA, Glynn NW, King AC, et al. Use of accelerometry to measure physical activity in older adults at risk for mobility disability. J Aging Phys Act 2008;16:416-34

40. Theou O, Jones G, Vandervoort A, et al. Daily muscle activity and quiescence in non-frail, pre-frail, and frail older women. Exp Gerontol 2010;45:909-17.

41. Theou O, Jakobi J, Vandervoort A, et al. A comparison of physical activity assessment tools across levels of frailty. Arch Gerontol Geriatr 2012;54:e307-14.
42. Taraldsen K, Askim T, Sletvold O, et al. Evaluation of a body-worn sensor sys tem to measure physical activity in older people with impaired function. Phys Ther 2011;91:277-85.

43. Jørstad-Stein EC, Hauer K, Becker C, et al. Suitability of physical activity questionnaires for older adults in fall-prevention trials: a systematic review. J Aging Phys Act 2005;13:461-81.

44. van Uffelen JG, Heesch KC, Hill RL, et al. A qualitative study of older adults responses to sitting-time questions: Do we get the information we want? BMC Public Health 2011;11:458.

45. Warburton DE, Bredin SS. Reflections on physical activity and health: What should we recommend? Can J Cardiol 2016;32:495-504.

46. Tremblay MS, Carson V, Chaput JP, et al. Canadian 24-hour movement guidelines for children and youth: an integration of physical activity, sedentary behaviour, and sleep. Appl Physiol Nutr Metab 2016;41(6 Suppl 3): S311-27.
Competing interests: Kenneth Rockwood is a founder and director of DGI Clinical Inc., attended a Roche advisory board meeting concerning outcome measurement for Alzheimer disease and has received speaker's fees from Nutricia. No other competing interests were declared.

This article has been peer reviewed.

Affiliations: Division of Geriatric Medicine (Theou, Godin, Rockwood), Dalhousie University, Halifax, NS; MRC Unit for Lifelong Health and Ageing (Blodgett), University College London, London, UK

Contributors: Olga Theou contributed to the conception and design of the study and to the analysis and interpretation of data. Joanna Blodgett contributed to the design and to acquisition, analysis and interpretation of data. Judith Godin contributed to the analysis and interpretation of data. Kenneth Rockwood contributed to the conception and design. All of the authors drafted the manuscript, revised it critically for important intellectual content, approved the version to be published and agreed to act as guarantors of the work.

Funding: Kenneth Rockwood receives funding from the Dalhousie Medical Research Foundation as Kathryn Allen Weldon Professor of Alzheimer Research.

Accepted: Apr. 11, 2017

Correspondence to: Olga Theou, olga.theou@dal.ca 